\title{
Genesis
}

Manuscrits - Recherche - Invention

39 | 2014

Avant-dire

\section{L'Assommoir et Mon voisin Jacques d'Émile Zola : étude comparée de la genèse des personnages secondaires}

Midori Nakamura

\section{(2) OpenEdition \\ Journals}

Édition électronique

URL : http://journals.openedition.org/genesis/1401

DOI : 10.4000/genesis. 1401

ISSN : 2268-1590

Éditeur :

Presses universitaires de Paris Sorbonne (PUPS), Société internationale de génétique artistique littéraire et scientifique (SIGALES)

Édition imprimée

Date de publication : 17 novembre 2014

Pagination : 183-200

ISBN : 9782840509714

ISSN : 1167-5101

Référence électronique

Midori Nakamura, «L'Assommoir et Mon voisin Jacques d'Émile Zola : étude comparée de la genèse des personnages secondaires », Genesis [En ligne], 39 | 2014, mis en ligne le 21 décembre 2016, consulté le 01 mai 2019. URL : http://journals.openedition.org/genesis/1401; DOI : 10.4000/genesis. 1401 


\title{
L'Assommoir et Mon voisin Jacques d'Émile Zola : étude comparée de la genèse des personnages secondaires
}

\author{
Midori Nakamura*
}

$\mathrm{S}$ i les personnages principaux d'un roman ont ordinairement une relation directe avec les actions de l'histoire, ses personnages secondaires en forment l'arrière-plan. Mais lorsqu'on se penche avec attention sur ces derniers, on constate qu'ils n'en sont pas moins investis de fonctions spécifiques et nécessaires au récit ${ }^{1}$. Si bien qu'une enquête sur la genèse des personnages dans les manuscrits nous met bien souvent sur les traces de l'esthétique singulière que l'écrivain a appliquée à sa création.

Nous nous intéresserons ici au personnage nommé Bazouge, qui exerce le métier de croque-mort dans L'Assommoir (1876) d'Émile Zola. Ce roman, le septième volume du cycle des Rougon-Macquart, décrit la vie d'une blanchisseuse, Gervaise, en l'insérant dans une galerie de tableaux pittoresques d'un quartier ouvrier pauvre de Paris sous le Second Empire. Abandonnée à la misère par son amant au début du récit, l'héroïne ne ménage pas ses efforts pour accéder à un bonheur modeste, grâce à son mariage avec un honnête zingueur, Coupeau, puis à l'ouverture de sa propre boutique. Mais Coupeau tombé d'un toit sombre alors dans l'alcoolisme, entraînant dans sa chute Gervaise, dont l'ancien amant est de retour : la voilà qui glisse elle aussi progressivement dans l'alcoolisme, avant de connaître une mort infâme, dans la crasse.

Bien que doté en tout et pour tout de cinq apparitions qui peuvent paraître anecdotiques, le personnage en question, Bazouge, ne laisse pas d'assumer un rôle important, puisqu'il lui revient d'annoncer à l'héroïne la mort qui lui est réservée. À chacune de leurs rencontres, il est la figure sinistre qui relie le destin funeste de
Gervaise à la fatalité de la misère humaine ${ }^{2}$ : « Ça ne vous empêchera pas d'y passer, ma petite... Vous serez peutêtre bien contente d'y passer, un jour... Oui, j'en connais des femmes, qui diraient merci, si on les emportait ${ }^{3}$. »

Nous avons exploré la genèse de ce personnage dans les dossiers préparatoires de l'écrivain. L'analyse scrupuleuse de ces dossiers nous a révélé un fait intéressant : Bazouge est issu d'une ramification d'un personnage primitif, dont provient également le père Bru, figure de second plan incarnant la misère de l'ouvrier. Or nous savons par ailleurs que la figure du croque-mort tire sa source de Mon voisin Jacques ${ }^{4}$, un conte écrit auparavant par Zola. La question qui se pose est dès lors celle de l'influence que ce modèle préexistant a pu exercer sur les modalités de la scission du personnage primitif. Nous commencerons donc par examiner le dossier préparatoire de L'Assommoir, en nous attachant

\footnotetext{
* La présente recherche bénéficie de l'aide de KAKENHI (25884058), accordé par la Société japonaise pour la promotion des sciences (JSPS). 1. Voir Philippe Hamon, Le Personnel du roman, Genève, Droz, 1983, p. 297.

2. Sur la technique narrative de l'« annonce », voir notre thèse de doctorat : «Les "annonces" narratives dans les romans d'Émile Zola », Université Paris III, soutenue en 2012 sous la direction du Professeur Alain Pagès.

3. Toutes les citations de ce roman sont tirées de l'édition suivante : Émile Zola, L'Assommoir [1876], dans Les Rougon-Macquart, t. II, édition intégrale publiée sous la direction d'Armand Lanoux, études, notes et variantes par Henri Mitterand, Paris, Gallimard, coll. « Bibliothèque de la Pléiade », 2007 [1961], p. 463.

4. Plusieurs versions de ce conte ont d'abord paru dans des journaux, avant qu'il ne soit finalement inclus dans le recueil des Nouveaux Contes à Ninon (1874). Le personnage du croque-mort y joue un rôle primordial.
} 


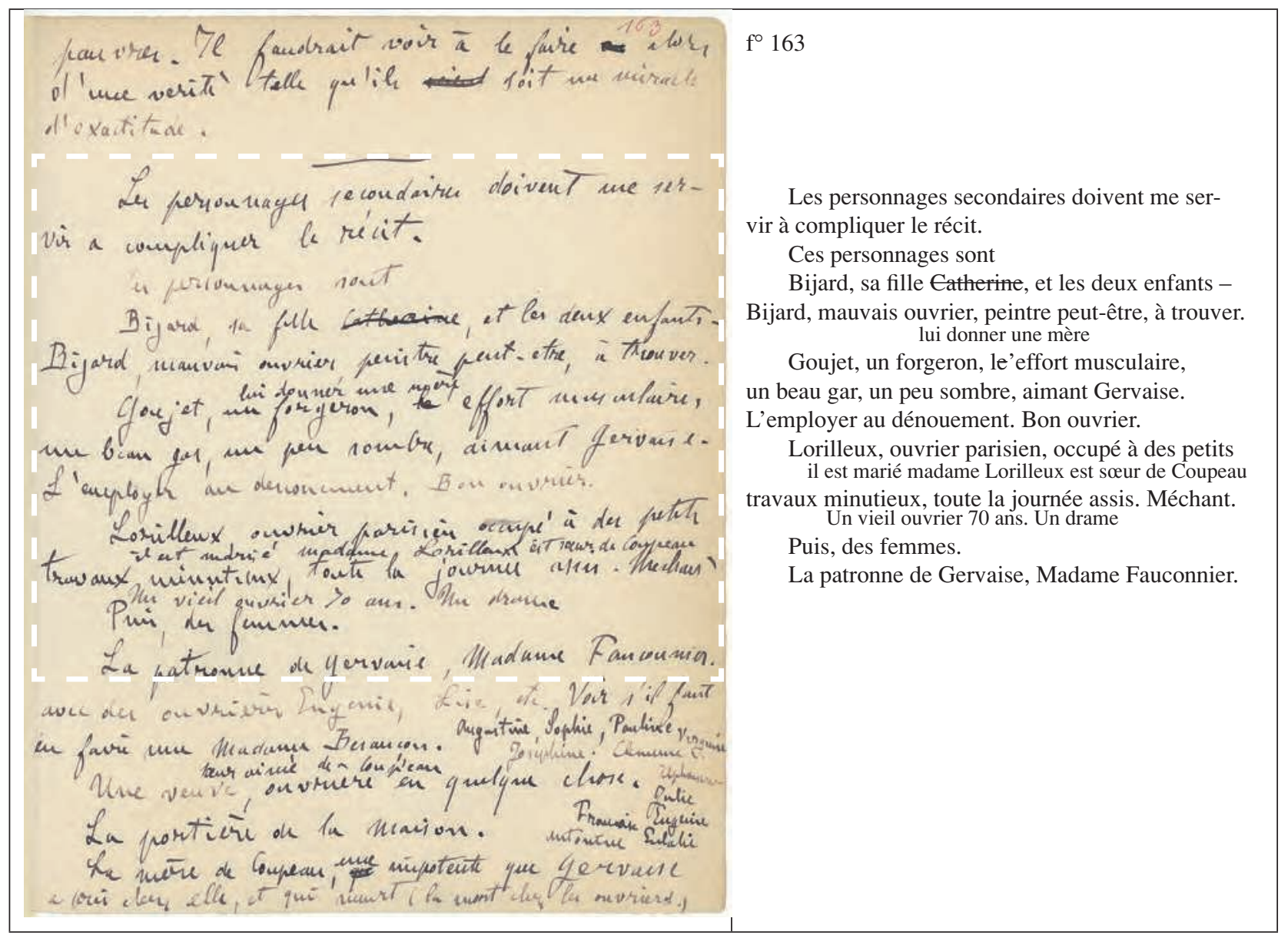

surtout aux feuillets qui concernent les deux personnages jumeaux. Puis nous remonterons à la source de la figure du croque-mort, jusqu'à Mon voisin Jacques. Nous tenterons enfin de comparer les différents aspects que cette figure revêt dans le conte et dans le roman ${ }^{5}$.

\section{La confusion et la division des personnages : Bazouge et le père Bru}

\section{Portrait des personnages}

Précisons, pour commencer, que le dossier préparatoire de L'Assommoir, NAF 10271, est conservé au département des Manuscrits de la Bibliothèque nationale de France 6 . Comme pour ses autres romans, l'écrivain a classé ses dossiers en plusieurs rubriques, «Ébauche », «Personnages », «Plan général », « Plan détaillé », etc. 7 .

Avant d'entreprendre leur étude détaillée, il est nécessaire de les classer selon l'ordre chronologique de la rédaction, sur lequel la numérotation des folios effectuée par la Bibliothèque nationale de France ne fournit aucun renseignement. Il y a, certes, des détails anachroniques complexes, l'ordre approximatif de la rédaction peut être reconstitué comme suit, d'après la notice d'Henri Mitterand dans l'édition de la Pléiade : Zola a commencé par l'« Ébauche », avant de s'atteler aux « Personnages », puis de passer au «Plan général », suivi du « Premier plan détaillé », enfin du « Deuxième plan détaillé ». Même si cet ordre de la genèse reste une hypothèse, il sera néanmoins utile afin d'entamer notre analyse.

L'acte de naissance de Bazouge se trouve au folio 163 de l'Ébauche (voir ci-dessus).

5. Le présent article reprend et développe le deuxième chapitre de la deuxième partie de notre thèse, ainsi qu'un article en japonais : Midori Nakamura, «Izakaya ni okeru tôjô jinbutsu no bunka - "yokoku" no mondai wo megutte » [La division des personnages dans L'Assommoir - la problématique de 1'《annonce »], Études de langue et littérature françaises du Kansai, $\mathrm{n}^{\circ}$ 14, Société japonaise de langue et littérature françaises du Kansai, Kyoto, p. 57-68.

6. Nous avons retranscrit les manuscrits cités dans le texte, à l'aide de l'édition suivante : La Fabrique des Rougon-Macquart : édition des dossiers préparatoires, vol. II, publié par Colette Becker, avec la collaboration de Véronique Lavielle, Paris, Honoré Champion, 2005.

7. L' « Ébauche » est un document où le romancier note rapidement un sujet, une intrigue ou des rôles; la rubrique « Personnages » contient des fiches de description de chaque personnage ; le «Plan général » consiste le plus souvent en un ou deux feuillets sur lesquels le romancier inscrit la liste des chapitres, accompagnée de la mention des événements importants ; le «Plan détaillé » est enrichi, chapitre après chapitre, d'informations et d'épisodes mineurs, au fur et à mesure du travail de documentation et de programmation. 


\begin{tabular}{|c|c|}
\hline 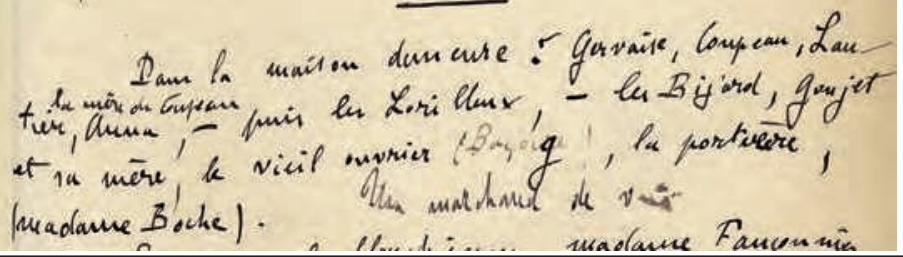 & $\begin{array}{l}\mathrm{f}^{\circ} 164 \\
\quad \text { Dans la maison demeure : Gervaise, Coupeau, Lan- } \\
\text { la mère de Coupeau } \\
\text { tier, Anna, - puis les Lorilleux, - les Bijard, Goujet } \\
\text { et sa mère, le vieil ouvrier (Bazouge), la portière, } \\
\text { (madame Boche). Un marchand de vin }\end{array}$ \\
\hline
\end{tabular}

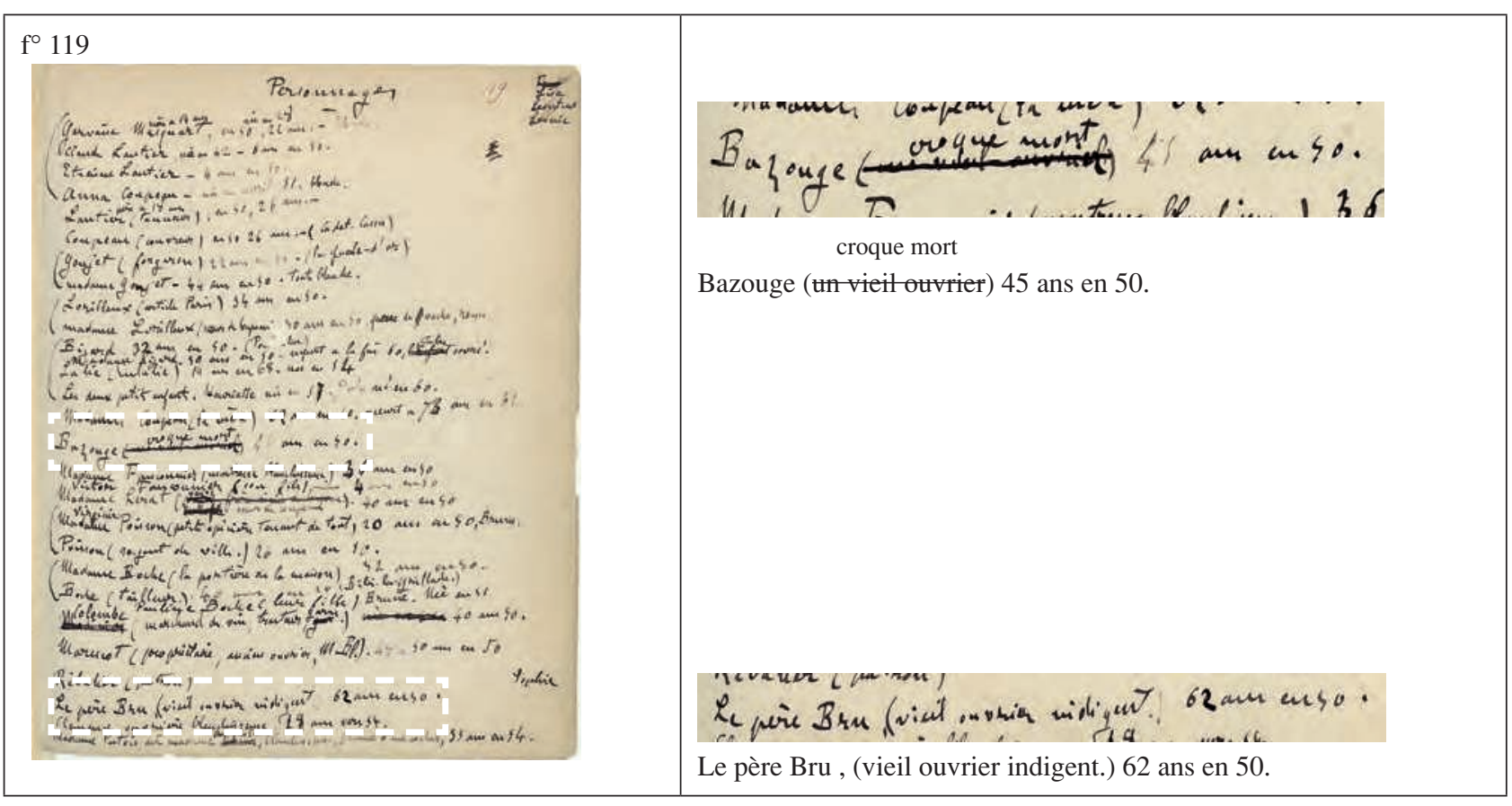

Zola énumère ici les futurs personnages secondaires avec leurs noms, Bijard, Goujet ou Lorilleux, accompagnés de l'indication de leur métier. Mais il ajoute un personnage anonyme noté en petits caractères : « un vieil ouvrier 70 ans. Un drame ». Ici, on ne trouve aucun nom, ni d'indication précise sur le métier. À ce stade, cette mention paraît correspondre à un autre personnage que Bazouge, lequel, dans le roman publié, fait sa première apparition au chapitre III en tant que « croque-mort d'une cinquantaine d'années 8 ». On pense plutôt à un dénommé « père Bru », présenté à sa première entrée en scène au chapitre VI comme « un ancien ouvrier peintre, un vieillard de soixante-dix ans, qui habitait dans la maison une soupente, où il crevait de faim et de froid $^{9}$ ». Ce dernier vit très pauvrement parce qu'il ne peut plus travailler depuis deux ans. Aussi l'indication du personnage anonyme dans le folio 163 semble-t-elle désigner plutôt le père Bru.

Remarquons, à propos de ce folio, que Zola énumère les personnages secondaires masculins, avant de commencer la série des personnages secondaires féminins après les mots : «Puis, des femmes ». La note sur le vieil ouvrier s'est glissée entre ces deux parties. Ainsi, c'est seulement après avoir commencé à réfléchir aux femmes du roman que Zola a eu l'idée d'un nouveau personnage masculin lié à un « drame » quelconque, ajoutant dès lors une notule à la fin de la série des hommes.

Dans la page suivante, au folio 164 (voir ci-dessus), ce premier essai d'identification est cependant remis en question. C'est dans l'énumération des habitants de la Goutte d'Or que « le vieil ouvrier » se voit pour la première fois accoler le nom de «Bazouge », d'une écriture, entre parenthèses, qui semble trahir une hésitation. Aurions-nous fait fausse route en identifiant « le vieil ouvrier de 70 ans » au père Bru ? Peut-être. Remarquons néanmoins que les précisions sur le métier continuent à faire défaut. Ce n'est qu'une fois l'Ébauche close qu'on les trouvera enfin, dans les fiches de «Personnages ».

La rubrique «Personnages » comprend une liste tenant sur un feuillet, complétée par des fiches individuelles détaillées. Dans cette liste de personnages, folio 119, Zola donne les noms avec de simples notes sur le métier et l'âge (voir ci-dessus).

8. L'Assommoir, op. cit., p. 462.

9. Ibid., p. 552. 


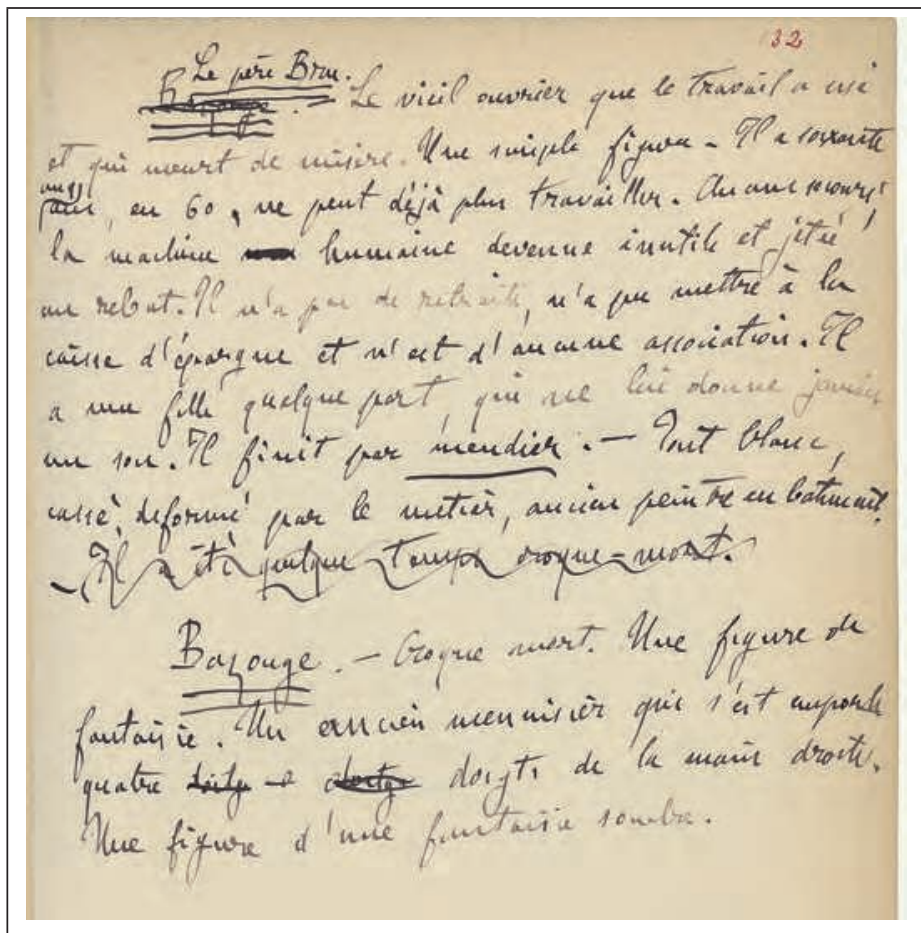

$f^{\circ} 132$

\section{Le père Bru.}

Bazuge. - Le vieil ouvrier que le travail a usé et qui meurt de misère. Une simple figure - il a soixante cinq

ans, en 60 , ne peut déjà plus travailler. Aucun secours, la machine um humaine devenue inutile et jetée au rebut. Il n'a pas de retraite, n'a pu mettre à la caisse d'épargne et n'est d'aucune association. Il a une fille quelque part, qui ne lui donne jamais un sou. Il finit par mendier. - Tout blanc, cassé, déformé par le métier, ancien peintre en bâtiment. - Hl a été quelque temps eroque-mort.

Bazouge - Croque mort. Une figure de fantaisie. Un ancien menuisier qui s'est emporté quatre toigt $\theta$ doigts doigts de la main droite. Une figure d'une fantaisie sombre.

Au milieu de la liste, le nom de Bazouge est d'abord accompagné d'une indication entre parenthèses : « (un vieil ouvrier) », raturée et remplacée par « croque mort ». Estce ici la première fois que l'écrivain donne à Bazouge la profession de croque-mort ? Par ailleurs, son âge, « 45 ans en $50 »$, est proche de celui de la version définitive, une « cinquantaine d'années ». En revanche, au bas de la page, le nom du père Bru apparaît, suivi de l'indication « vieil ouvrier indigent. » Les mots « vieil ouvrier », raturés dans la présentation de Bazouge, sont repris dans celle du père Bru, augmentés de l'adjectif « indigent ». Son âge, « 62 ans en 50 », est à peu près cohérent avec le portrait tracé de lui dans le roman : lors de son entrée en scène, au sixième chapitre du récit, qui se déroule en 1855, il doit avoir autour de 70 ans. On voit donc comment l'hésitation de Zola au moment d'attribuer le statut de vieil ouvrier à Bazouge, s'est soldée par la création d'un autre personnage : le père Bru.

On décèle des traces de cette même hésitation dans les fiches des personnages. Au folio 132 (voir ci-dessus), le romancier commence à décrire ainsi la figure de Bazouge.

«Bazouge. - Le vieil ouvrier que le travail a usé et qui meurt de misère. » Mais le nom de Bazouge est rayé et remplacé par «Le père Bru » inscrit au-dessus. Par ailleurs, à la dernière ligne du portrait de ce personnage, une phrase importante est raturée : «Il a été quelque temps croque-mort. »C'est vraisemblablement ici que ce métier apparaît pour la première fois dans les dossiers préparatoires. Il est ici intéressant que, tout de suite après cette rature, la rubrique de Bazouge s'ouvre de nouveau, accompagnée de la précision laconique: « Croque mort. »
Essayons de résumer les étapes de la genèse jusqu'au stade auquel nous sommes parvenu. Au début, dans le folio 163 de l'Ébauche, il n'y avait qu'un personnage anonyme, qualifié de vieil ouvrier. Au folio 164 suivant, Zola lui a donné le nom de Bazouge. Cet état prévaut encore dans la liste des personnages au folio 119. Pourtant, au folio 132, après avoir prêté à ce Bazougeouvrier une ancienne carrière de croque-mort, le romancier a probablement trouvé peu convenable qu'un même personnage porte conjointement cette double identité de métier. Il s'est décidé ainsi à le dédoubler, pour en tirer un vieil ouvrier et un croque-mort distincts l'un de l'autre. Comme le métier de croque-mort était réservé à Bazouge, il lui fallait un autre nom pour l'ouvrier. Ainsi Zola a-t-il nommé celui-ci le père Bru. Il est ensuite retourné à la liste du folio 119 pour y ajouter ce nouveau personnage au bas de la page.

\section{Distribution des entrées en scène}

Malgré cet effort pour distinguer les deux personnages, on a l'impression que leurs fonctions ne sont pas encore nettement définies dans la série des plans qui font suite à la liste des personnages («Plan général », « Premier plan détaillé » et «Deuxième plan détaillé »). Par exemple, les trois plans établissent entre leurs entrées en scène une concomitance que le roman publié abandonnera complètement. 


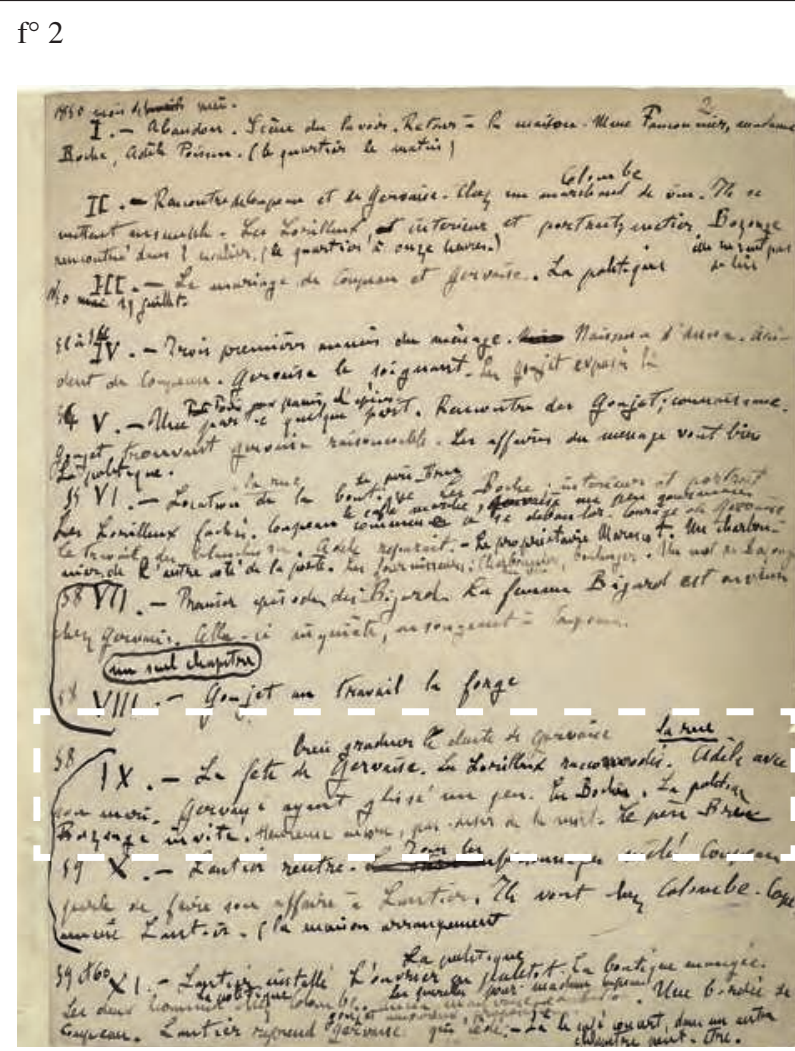

$\mathrm{f}^{\circ} 3$

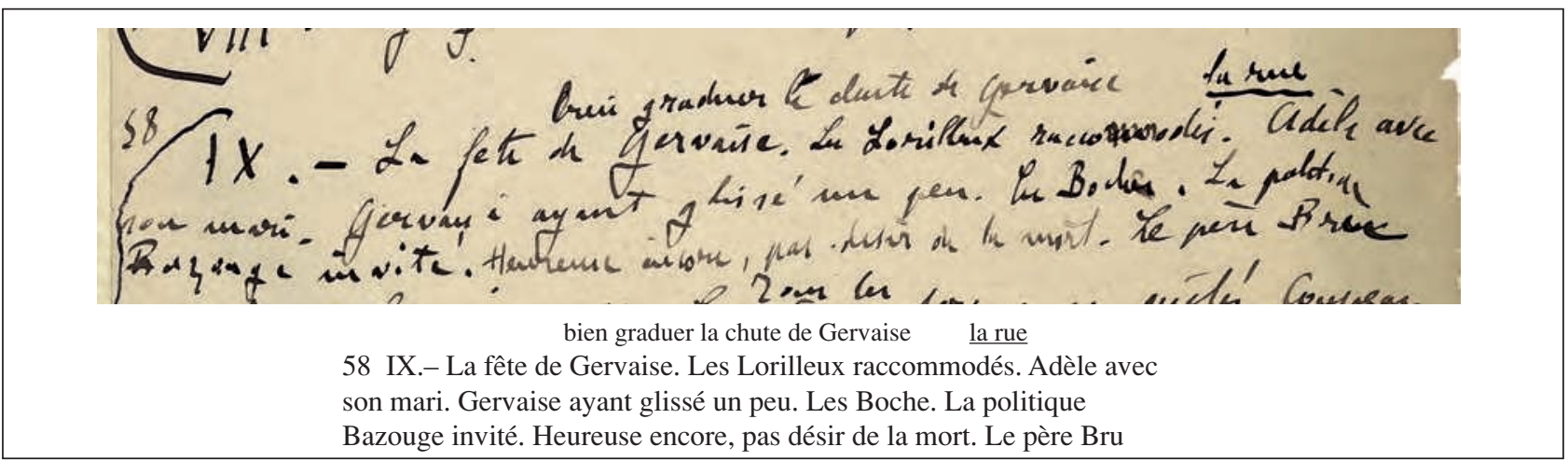

\section{La fête de Gervaise}

Il faut préciser que, dans ces trois plans, la structure de l'intrigue principale diffère peu de celle de la version définitive. La différence essentielle entre celle-ci et ceux-là tient à la disposition des chapitres ${ }^{10}$. Le «Plan général » et le « Premier plan détaillé » contiennent vingt et un chapitres, tandis que le "Deuxième plan détaillé » se compose de treize chapitres, comme la version publiée. Quoi qu'il en soit, dans ces quatre versions, la fameuse fête de Gervaise se situe au milieu de l'histoire.

Or cette fête, dans la version finale, est connue pour le passage, bref mais signifiant, où Gervaise décide à la dernière minute d'amener le père Bru au banquet, en tant que quatorzième convive, pour éviter le nombre sinistre de treize personnes à table. Le croque-mort Bazouge, quant à lui, n'en fait pas partie. Or il n'en allait pas ainsi dans les trois plans, où Bazouge était invité à la fête en même temps que le père Bru. Voyons d'abord le «Plan général » (fos 2-3, voir ci-dessus).

10. Pour le travail arithmétique de Zola sur le chapitrage, voir David Baguley, «Event and Structure: The Plot of Zola's L'Assommoir », PMLA, vol. 90, $\mathrm{n}^{\circ}$ 5, octobre 1975, p. 823-833; Jacques Allard, Zola, le chiffre du texte, Grenoble, Presses universitaires de Grenoble, 1978 ; Henri Mitterand, « Programme et préconstruit génétiques : le dossier de L'Assommoir », dans Essais de critique génétique, Paris, Flammarion, coll. « Textes et manuscrits », 1979 ; Jean-Pierre Leduc-Adine, « Dossiers préparatoires et genèse scénarique chez Zola », Manuscrítica. Revista de Crítica Genética, $\mathrm{n}^{\circ} 7,1998$, p. 59-68. 


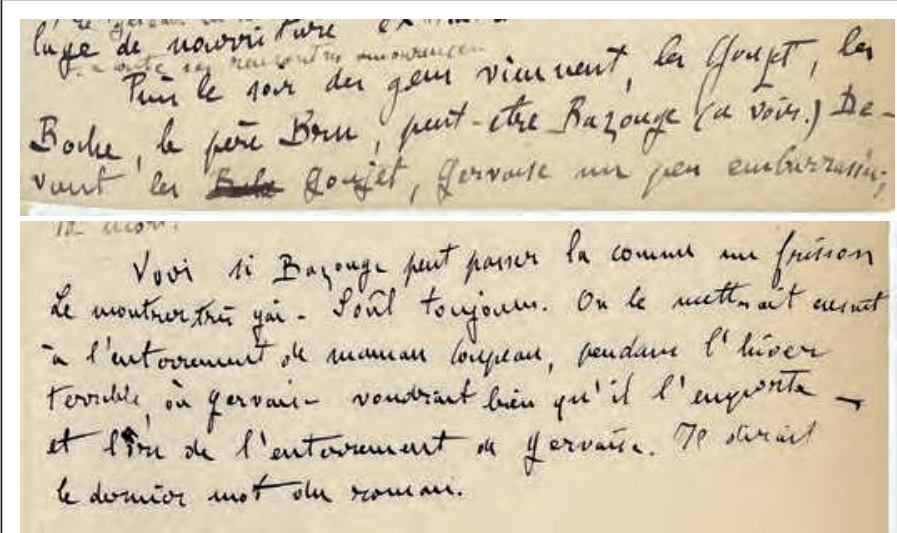

$f^{\circ} 37$

Puis le soir des gens viennent, les Goujet, les Boche, le père Bru, peut-être Bazouge (à voir). Devant les Boehe Goujet, Gervaise un peu embarrassée ; $\mathrm{f}^{\circ} 38$

Voir si Bazouge peut passer là comme un frisson Le montrer très gai. Soûl toujours. On le mettrait ensuit à l'enterrement de maman Coupeau, pendant l'hiver terrible, où Gervaise voudrait bien qu'il l'emporte et lors de l'enterrement de Gervaise. Il dirait le dernier mot du roman.

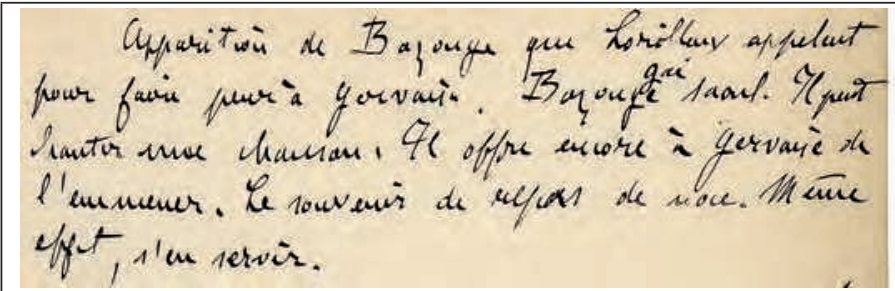

$\mathrm{f}^{\circ} 36$

Apparition de Bazouge que Lorilleux appelent pour faire peur à Gervaise. Bazouge saoul. Il peut chanter une chanson. Il offre encore à Gervaise de l'emmener. Le souvenir de repas de noce. Même effet, s'en servir.

Dans l'ancienne version du chapitre IX figure la mention «Bazouge invité ». Chose curieuse, cette mention est immédiatement suivie de la note : « Heureuse encore, pas désir de la mort. » Il s'agit bien sûr de l'héroïne, qui jouit encore d'une situation prospère et n'a donc aucune raison de vouloir mourir. Il est intéressant de noter que l'apparition de Bazouge est directement associée à une mise au point provisoire sur les sentiments de Gervaise. Ne manquons pas de noter également le nom du père Bru placé à côté.

Le «Premier plan détaillé » contient une référence plus précise à Bazouge. Dans ce plan, la scène de la fête est programmée au chapitre VIII (fos 37-38, voir ci-dessus).

Comme le montrent les notations «peut-être Bazouge (à voir) » ( $\left.\mathrm{f}^{\circ} 37\right)$ et «Voir si Bazouge peut passer là comme un frisson » ( $\left.{ }^{\circ} 38\right)$, le romancier hésite à ce moment-là à le mettre en scène. En même temps, il semble que Zola ait déjà en tête les autres scènes où Bazouge est destiné à apparaître, si l'on en juge par les phrases qui suivent : «On le mettrait ensuite à l'enterrement de maman Coupeau [...]. » Ce qui est en tout cas à retenir de ce folio 37 est que les noms du père Bru et de Bazouge y figurent à nouveau côte à côte.

Enfin, dans le «Deuxième plan détaillé », la fête est située au chapitre VII (fos 31-36), comme dans la version définitive. Mais Bazouge y apparaît à nouveau, dans le folio 36 (voir ci-dessus).

Il est indiqué que l'apparition de Bazouge a pour finalité de «faire peur à Gervaise ». Zola entend bien sûr par là la peur de la mort (« Il offre encore à Gervaise de l'emmener. »). À ce stade, le rôle de Bazouge semble peu à peu prendre corps : c'est celui d'un annonciateur sinistre. L'écrivain précise l'effet de ses paroles dans cette scène en renvoyant à sa première apparition lors du mariage de Gervaise (« Même effet, s'en servir »).

En même temps, on remarque toujours la coprésence de Bazouge et du père Bru. Le folio 35 (page suivante), de plus petit format que les autres 11 , dresse une liste des convives de la fête au-dessus des notes concernant le menu.

11. "Folio de format $15,5 \times 10 \mathrm{~cm} »$ (La Fabrique des RougonMacquart, op. cit., t. II, p. 806) 

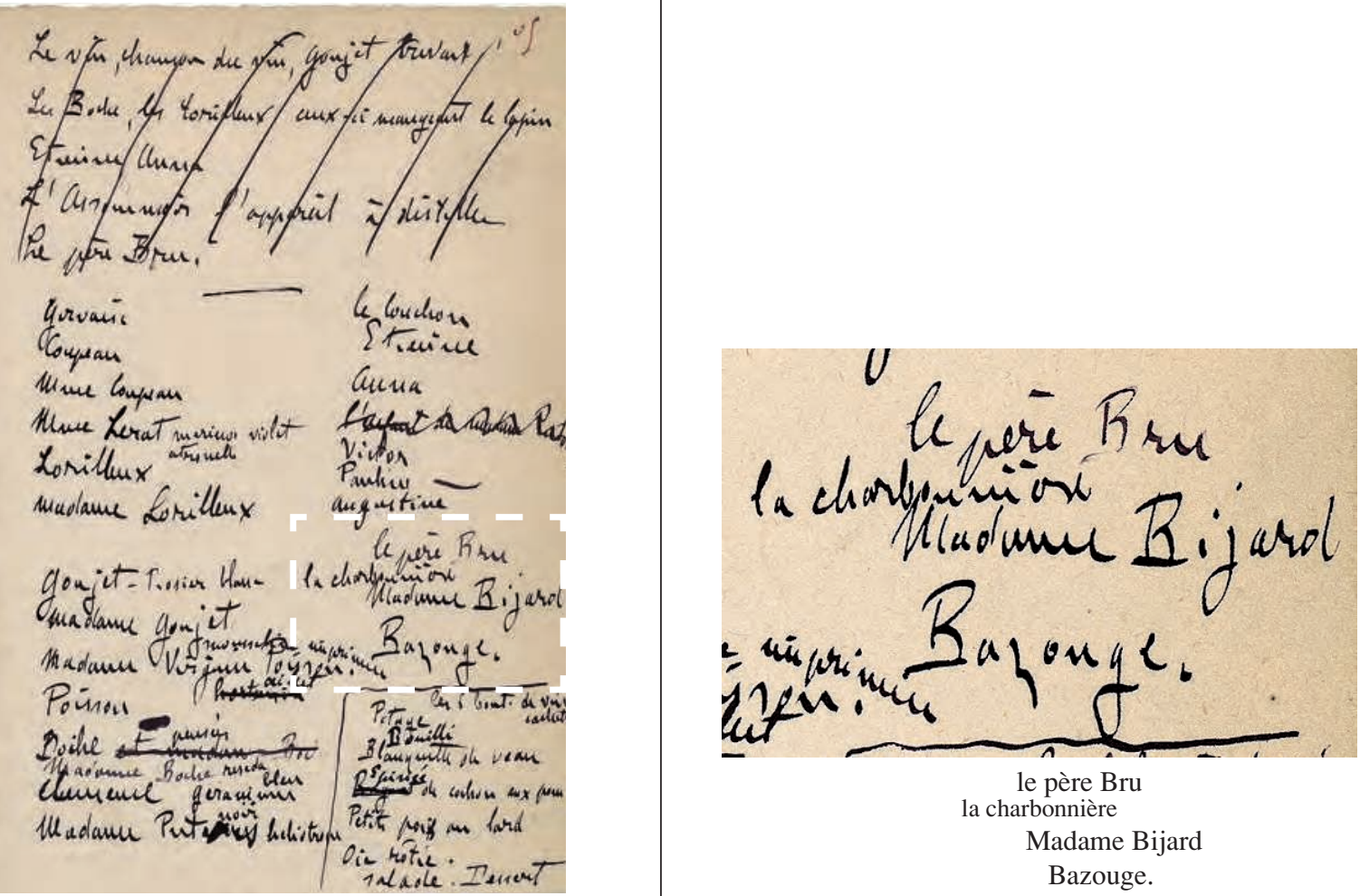

$\mathrm{f}^{\circ} 32$

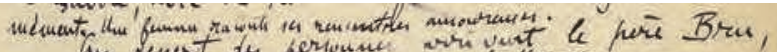

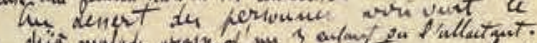

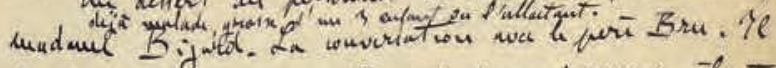

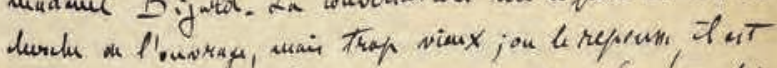

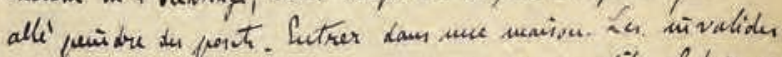

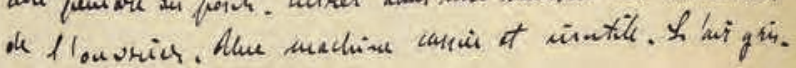
[...]

$\mathrm{Au}$ dessert des personnages arrivent le père Bru,

madame Bijard. La conversation avec le père Bru. Il cherche de l'ouvrage, mais trop vieux ; on le repousse, il est allé peindre des ponts. Entrer dans une maison. Les invalides de l'ouvrier. Une machine cassée et inutile. L'air gris.

Le père Bru et Bazouge voisinent toujours dans la même zone de la liste. On constate aussi que les convives sont plus nombreux que dans le roman, qui en compte quatorze. Toutefois, ce même « Deuxième plan détaillé » paraît enregistrer une rupture de la rédaction. Certains folios, en effet, semblent avoir été écrits postérieurement aux folios 35 et 36. Par exemple, le texte des folios 31 et 32 décrit les détails de la scène de la fête, mais, pour la première fois, Bazouge en est absent. À sa place, le père Bru est assez longuement décrit. On trouve justement, 


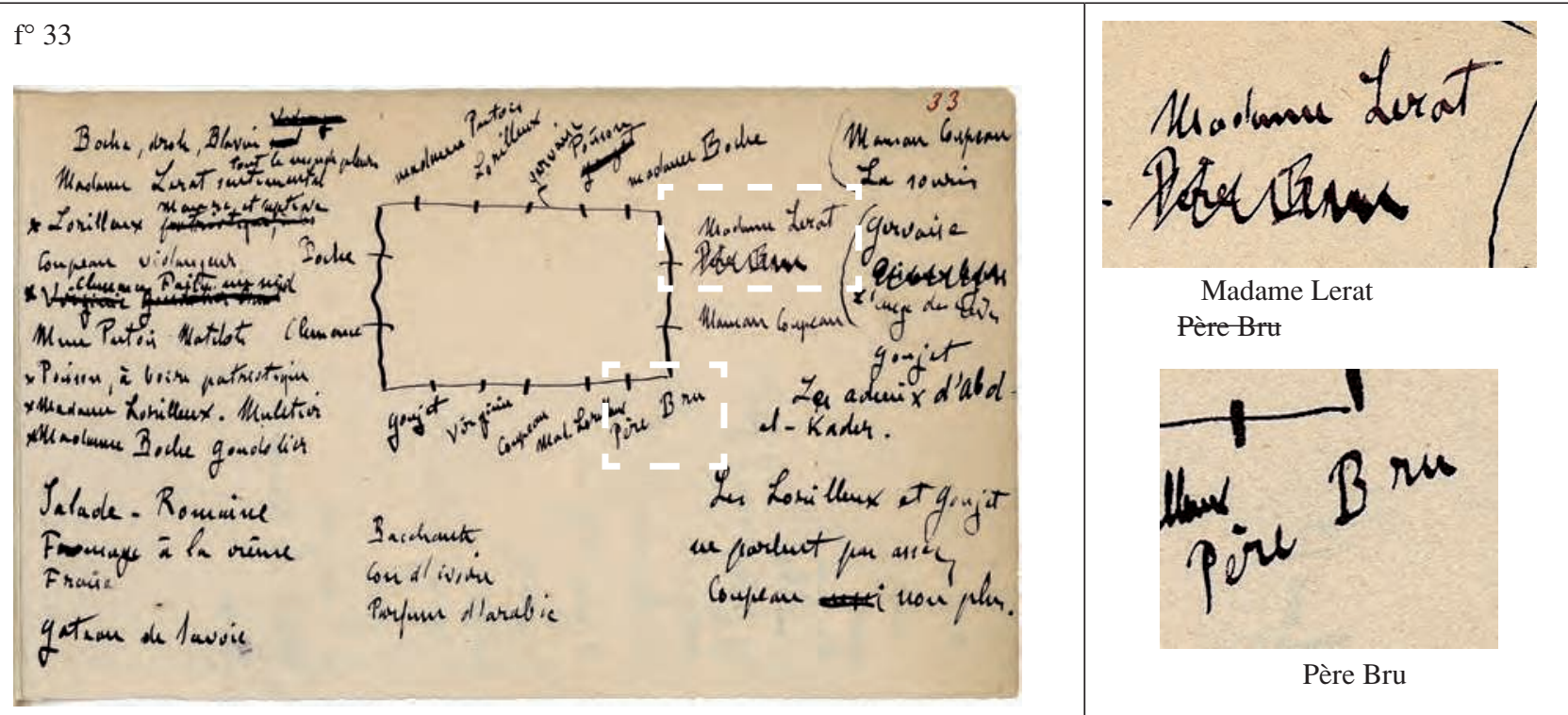

dans la version publiée, la conversation du père Bru avec d'autres personnages à propos de son travail et des «invalides de l'ouvrier ${ }^{12} »$.

De plus, il existe une autre liste des convives, avec le plan de la table du banquet : c'est le folio 33, qui est lui aussi d'un petit format ${ }^{13}$. Ici, le romancier va jusqu'à imaginer l'ordre des places autour de la table. Il n'y a plus de place pour Bazouge, alors que celle du père Bru est bien marquée. Inscrit auparavant en haut à droite du rectangle dessiné de la table, il cède sa place à Madame Lerat, pour être déplacé dans le coin inférieur droit. Parallèlement, le nombre de convives est finalement fixé à quatorze. C'est à ce moment-là que Zola a dû avoir l'inspiration de l'épisode du nombre treize. On en inférera logiquement que la rédaction des folios 31-33, qui établissent la liste définitive des quatorze convives, vient après celle des folios 35-36, qui comportent un plus grand nombre d'invités. On peut en déduire que le « Deuxième plan détaillé » a déjà connu un développement du scénario, qui a déterminé l'auteur à faire disparaître Bazouge. Celui-ci s'efface alors complètement de la scène de la fête, tandis que le père Bru y reste.
Nous avons constaté la disparition de Bazouge d'une scène où la première étape de la genèse le faisait cohabiter avec le père Bru. Pour cette scène de la fête de Gervaise, au début de la conception du roman, l'accent devait être mis sur la figure sinistre du croque-mort, mais celle du père Bru, qui incarne la misère humaine, l'a remplacée dans cette fonction.

\section{L'enterrement de la mère Coupeau}

Le processus est similaire s'agissant de la scène de l'enterrement de la mère Coupeau. D'après les deux premiers plans conçus par Zola, le vieil ouvrier et le croque-mort devaient tous deux y assister. Leur coprésence est marquée par la juxtaposition de leurs noms d'abord dans le «plan général » au folio 3 (page suivante).

L'ancien état du chapitre XIII porte les noms du père Bru et de Bazouge ajoutés à la même ligne en marge, à gauche et à droite. Il semble que ces noms s'appellent réciproquement.

12. L'Assommoir, op. cit., p. 582-583.

13. «Folio de format $9,5 \times 15,5 \mathrm{~cm} »$ (La Fabrique des RougonMacquart, op. cit., p. 802). 
$\mathrm{f}^{\circ} 3$

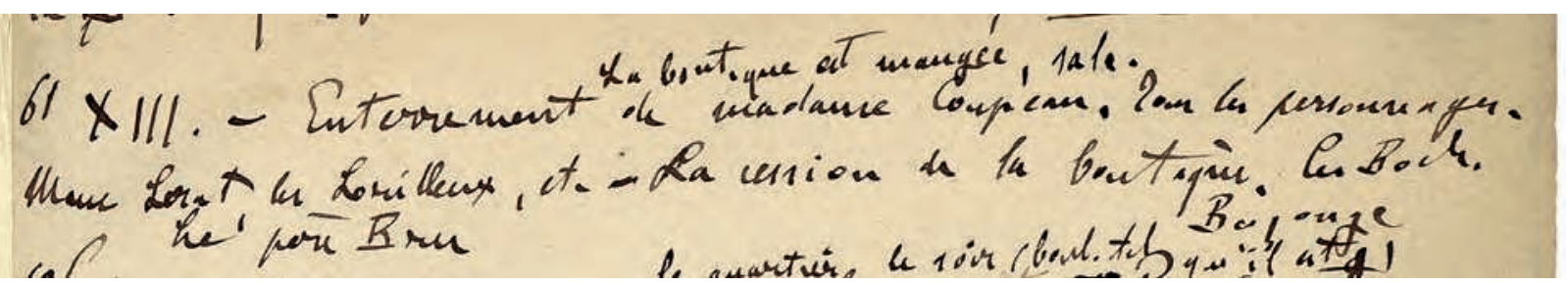

La boutique est mangée, sale.

61 XIII. - Enterrement de madame Coupeau. Tous les personnages.

Mme Lerat, les Lorilleux, etc. - La cession de la boutique. les Boche.

Le père Bru

Bazouge

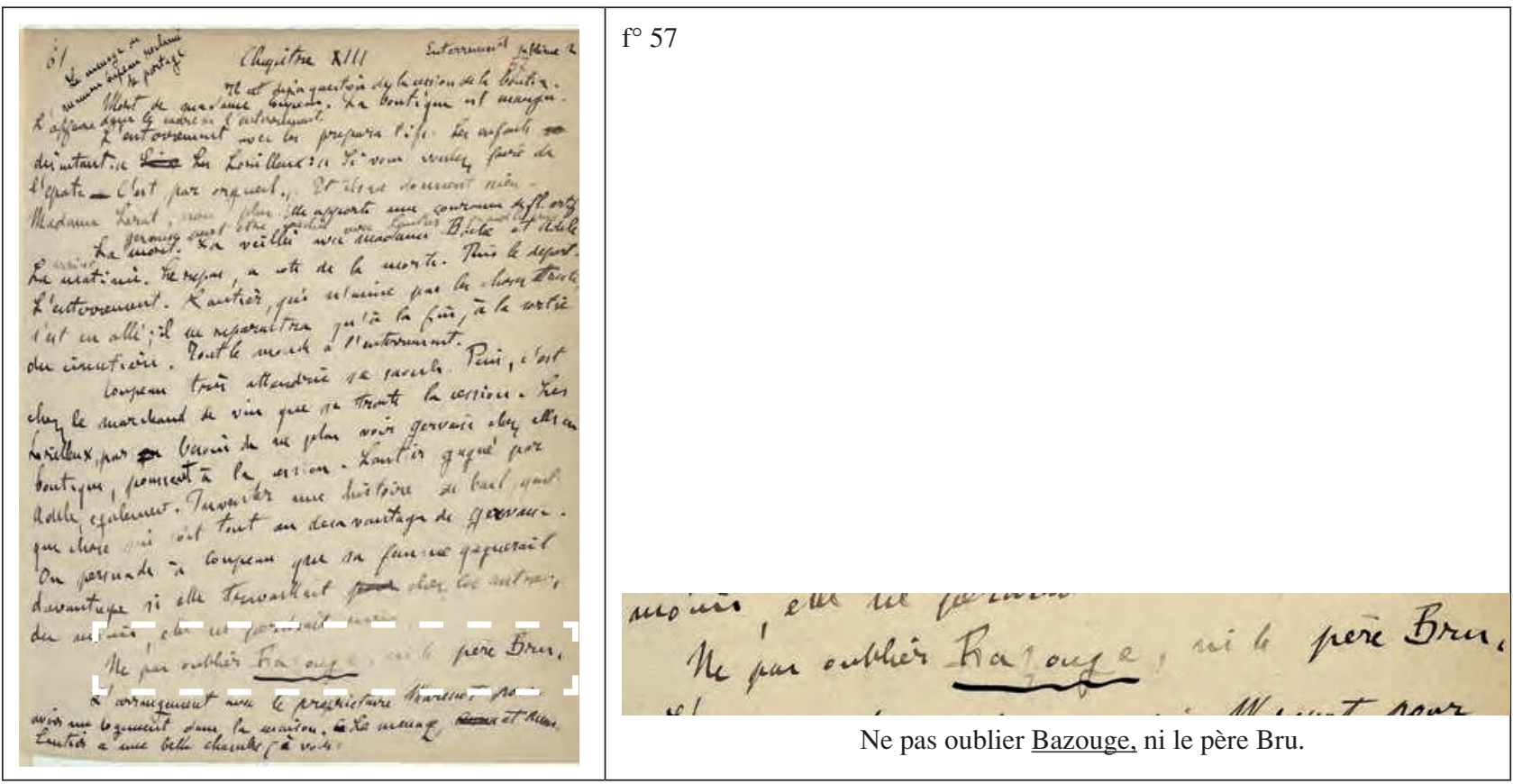

La version du chapitre XIII prévue par le «Premier plan détaillé » présente aussi ces deux noms juxtaposés dans la scène de l'enterrement de Madame Coupeau (voir $\mathrm{f}^{\circ} 57$ ci-dessus).
Bazouge étant croque-mort, il est naturel qu'il assiste à l'enterrement. Mais le père Bru est également mis en relief, à côté de lui. 


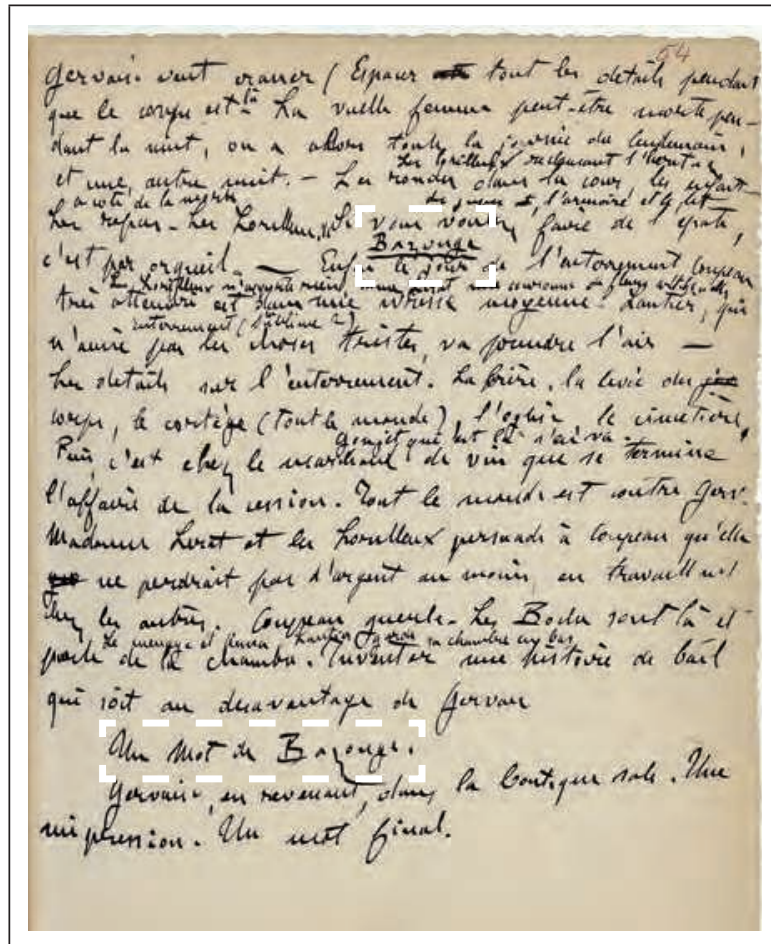

$f^{\circ} 54$

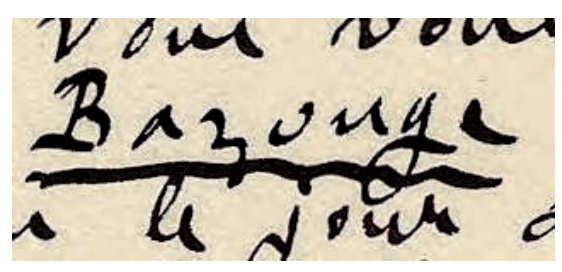

Bazouge

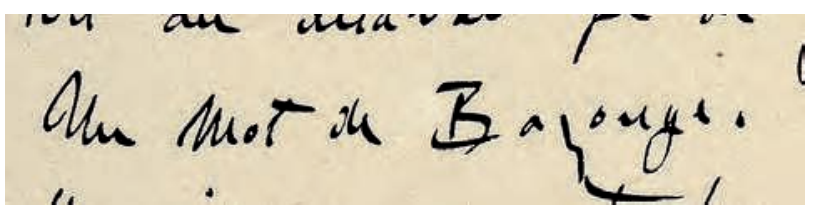

Un Mot de Bazouge.
Cependant, dans le «Deuxième plan détaillé », le père Bru n'apparaît plus. La scène de l'enterrement programmée au chapitre IX ne porte plus que le nom de Bazouge (voir $\mathrm{f}^{\circ} 54$ ci-dessus).

Cet état de fait est entériné par la version définitive. L'écrivain a supprimé le vieil ouvrier de cette scène, tout en gardant le croque-mort. Or, si la présence de Bazouge à l'enterrement s'explique aisément par son métier, l'exclusion du père Bru, qui tranche sur la présence de tous les amis des Coupeau dans le cortège, pose problème ${ }^{14}$.

Dans les deux passages que nous venons d'étudier celui de la fête de Gervaise et celui de l'enterrement de Madame Coupeau -, on observe la même stratégie : au cours du développement des plans, l'auteur a pris soin d'éviter la coprésence des deux personnages dans une même scène. Il en est même venu à établir une séparation formelle dans la distribution de leurs entrées en scène.
Qu'on en juge par le tableau chronologique des dossiers préparatoires (page suivante).

Posons une hypothèse : comme on l'a vu plus haut dans l'Ébauche, Zola a divisé le « vieil ouvrier » en deux personnages. Mais sans nettement distinguer, pendant un certain temps, leurs rôles respectifs. Il semble qu'il ait voulu d'abord leur déléguer le rôle d'émettre des mots sinistres, comme les notes du «Plan général » en témoignent : «Un mot de Bazouge » $\left(\mathrm{f}^{\circ} 2\right.$, chap. VI) ; «Un mot du père Bru » (fo 3 , chap. XIV) ; « Le dernier mot de Bazouge » $\left(\mathrm{f}^{\circ} 3\right.$, chap. XXI). Le « mot de Bazouge » peut facilement être rapporté à l'annonce allusive de la tentation de la mort que connaîtra Gervaise. Mais que peut bien signifier « un mot du père $B r u$ » $\left(f^{\circ} 3\right.$, chap. XIV, voir page suivante) ?

14. Voir la description du cortège dans L'Assommoir, op. cit., p. 667. 


\begin{tabular}{|c|c|c|}
\hline \multicolumn{3}{|c|}{ Les dossiers préparatoires de L’Assommoir (NAF 10271) } \\
\hline $\begin{array}{l}\text { Août } 1875 \\
\text { L'« Ébauche » (fos 157-173) }\end{array}$ & \multicolumn{2}{|c|}{$\begin{array}{l}\text { «Un vieil ouvrier } 70 \text { ans. Un drame » }\left(\mathrm{f}^{\circ} 163\right) \\
\text { «le vieil ouvrier (Bazouge)» }\left(\mathrm{f}^{\circ} 164\right)\end{array}$} \\
\hline «Personnages » (fos 118-138) & \multicolumn{2}{|c|}{$\begin{array}{l}\text { la liste des personnages } \\
\text { «Bazouge (vieil ouvrier) } 45 \text { ans en } 50 . »\left(f^{\circ} 119\right)\end{array}$} \\
\hline \multirow[t]{2}{*}{$\begin{array}{l}\text { Les feuillets des } \\
\text { personnages } \\
\text { (fos } 120-137 \text { ) }\end{array}$} & \multicolumn{2}{|c|}{$\begin{array}{l}\text { «Bazouge /Le père Bru/. - Le vieil ouvrier que le travail a usé }[. . .] \text { Il a été } \\
\text { quelque temps croque-mort. » } \\
\text { «Bazouge. - Croque-mort. Une figure de fantaisie. » }\left(f^{\circ} 132\right)\end{array}$} \\
\hline & \multicolumn{2}{|c|}{$\begin{array}{l}\text { «Bazouge ( } \\
\text { «Le père Bru (vieil ouvrier indigent.) } 62 \text { ans en 50.» }\left(\mathrm{f}^{\circ} 119\right)\end{array}$} \\
\hline & La fête de Gervaise & L'enterrement de Mme Coupeau \\
\hline «Plan général » (fos 2-3) & $\begin{array}{l}\text { « Bazọuge invité. Heureuse encore, } \\
\text { pas désir de la mort. Le père Brụ » } \\
\left(\mathrm{f}^{\circ} 2\right)(\text { chap. IX) }\end{array}$ & $\begin{array}{l}\text { «ẹe père Brụ / /Bạoụge » } \\
\left(\mathrm{f}^{\circ} 3\right) \text { (chap. XIII) }\end{array}$ \\
\hline «Premier plan détaillé » & 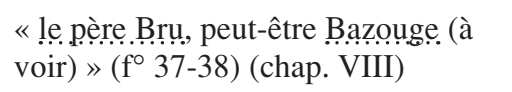 & 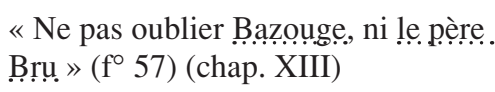 \\
\hline \multirow[t]{2}{*}{ «Deuxième plan détaillé » } & 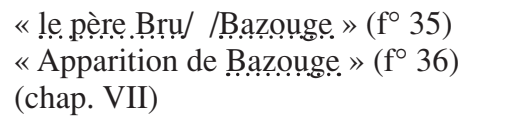 & \multirow[t]{2}{*}{$\begin{array}{l}\text { «Un mot de Bạạugẹ.: » (f॰ } 54) \\
\text { (chap. IX) } \\
\text { Disparition du père Bru. }\end{array}$} \\
\hline & $\begin{array}{l}\text { «La conversation avec le père Brẹu. » } \\
\left(f^{\circ} 32\right) \text { (chap. VII) } \\
\text { Disparition de Bazouge. }\end{array}$ & \\
\hline Version publiée & Entrée en scène du père Bru. & Entrée en scène de Bazouge. \\
\hline
\end{tabular}

\section{$\mathrm{f}^{\circ} 3$}

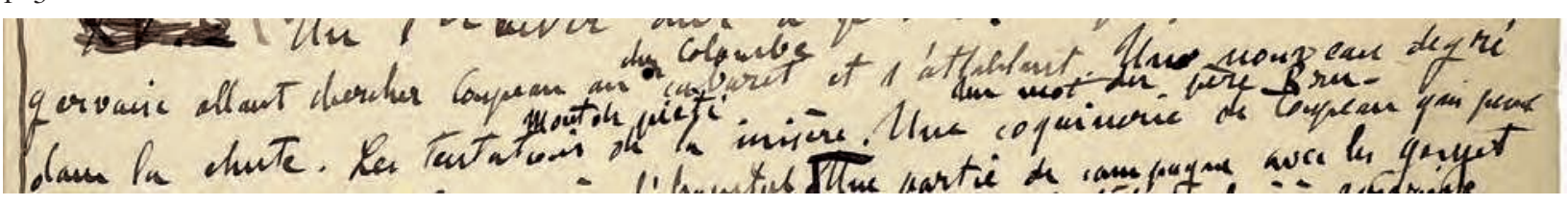

chez Colombe

Gervaise allant chercher Coupeau au cabaret et s'attablant. Une nouveau degré Mont de piété. Un mot du père Bru.

dans la chute. Les tentations de la misère. 
Les énoncés voisins, "Un nouveau degré dans la chute. Les tentations de la misère », suggèrent que ce mot était lui aussi destiné à annoncer la misérable fin de l'hérö̈ne.

Il est donc fort possible que, dans les deux premiers plans, le père Bru, lui aussi, ait eu à jouer le rôle d'annonciateur, tout à fait comme Bazouge, soit par ses propos, soit par son apparence lugubre. L'auteur prévoyait de les faire intervenir en même temps dans des scènes importantes, comme s'ils formaient une paire inséparable. Cependant, peu à peu, Zola est parvenu à distribuer les scènes les plus appropriées à chacun, ainsi la fête de Gervaise devait échoir au père Bru, et l'enterrement de Madame Coupeau à Bazouge.

Il en est résulté que les deux personnages ne se retrouvent plus jamais face à face dans la version définitive, malgré le fait qu'ils habitent le même immeuble. Pourquoi une séparation aussi stricte ? La question, qui reste pendante, requiert un détour par l'origine de ces deux personnages.

\section{L'origine du croque-mort : Mon voisin Jacques}

À propos de l'origine de la figure du croquemort, Henri Mitterand rappelle quelques éléments biographiques, dans sa préface au chapitre de Carnets d'enquêtes intitulé «De la rue de la Goutte-d'or à L'Assommoir » : «Zola avait vécu dans les quartiers pauvres de la rive gauche au début de son séjour à Paris, de 1858 à 1862. [...] Il avait là pour voisins des ouvriers, de petits employés, un croque-mort, dont le souvenir passera dans le personnage du vieux Bazouge 15. » Mitterand revient sur le sujet dans sa biographie de Zola : "Au plus fort de l'hiver, en effet, Émilie, Émile Zola et le grand-père Aubert s'en vont occuper un petit appartement 241, rue Saint-Jacques, à proximité du Val-de-Grâce [...]. C'est là sans doute que Zola croise tous les matins un croque-mort, qu'il appellera "mon voisin Jacques » dans Les Nouveaux Contes à Ninon, et qui donnera sa silhouette, dans L'Assommoir, à Bazouge 16. »

Mais Bazouge a-t-il vraiment son modèle dans la réalité ? Reportons-nous au conte Mon voisin Jacques ${ }^{17}$.

\section{La figure ambivalente de Jacques}

On trouve effectivement dans ce conte un croque-mort, Jacques, qui est assez proche de Bazouge. Au sujet du modèle de ce personnage, Roger Ripoll affirme dans sa notice : «Figures purement imaginaires : comme on le sait par Louis Desprez, qui avait interrogé Zola au sujet de Mon voisin Jacques, l'anecdote n'a aucun fondement réel ${ }^{18}$. »

Ledit Louis Desprez, dans L'Évolution naturaliste, s'était inscrit en faux contre la thèse de la source biographique, que Jules Claretie soutenait en ces termes : «On rencontre dans l'Assommoir un croque-mort nommé Bazouge. Ce croque-mort Zola fut son voisin. Dès 1869 , le romancier traçait ainsi le portrait de son ami Jacques ${ }^{19}$. » Après avoir reproduit cette citation, Desprez s'attache à la démentir :

J'avais lu, dans les Nouveaux contes à Ninon, sans y attacher d'importance biographique, la nouvelle intitulée Mon voisin Jacques. [...] Or, aujourd'hui, je suis désolé de contredire M. Claretie ; M. E. Zola n'a jamais cohabité avec un croque$\operatorname{mor}^{20}$.

Par ailleurs, l'enquête très fouillée de Colette Becker sur les immeubles parisiens que Zola a habités et sur les professions de leurs habitants n'a mis au jour aucun croque-mort ${ }^{21}$. Les deux thèses opposées demeurent finalement impossibles à départager, et l'origine du croque-mort reste mystérieuse. En tout cas, Zola ayant livré de ce conte, Mon voisin Jacques, quatre versions différentes dont les publications dans la presse s'échelonnent de 1865 à 187422, avant d'entreprendre la

15. Émile Zola, Carnets d' enquêtes. Une ethnographie inédite de la France, textes établis et présentés par Henri Mitterand, Paris, Plon, 1993, p. 415. 16. Henri Mitterand, Zola. Sous le regard d'Olympia 1840-1871, t. I, Paris, Fayard, 1999, p. 192.

17. Émile Zola, Mon voisin Jacques dans Contes et Nouvelles, op. cit., p. 435-439.

18. Ibid., p. 1363.

19. Louis Desprez, L'Évolution naturaliste, Paris, Tresse, 1884, p. 184. 20. Ibid., note de la page 185 .

21. Colette Becker, « Du garni à l'hôtel particulier : quelques aperçus sur la vie et l'œuvre de Zola à partir des calepins cadastraux », Les Cahiers naturalistes, $\mathrm{n}^{\circ} 43,1972$, p. 1-24.

22. En novembre 1865 dans le Journal des villes et des campagnes; le 3 novembre 1866 dans L'Événement; le 10 octobre 1869 dans La Tribune; le 24 juin 1872 dans La Cloche. 
rédaction de L'Assommoir en 1875 , il ne fait pas de doute que ce sujet lui tenait à cœur depuis longtemps.

Résumons brièvement l'argument de ce conte, d'après la version finale publiée dans le recueil Nouveaux Contes à Ninon chez Charpentier en 1874. Le héros, âgé de 20 ans, vit dans le grenier d'un immeuble, à côté d'une famille comprenant le père, la mère, et leur fille âgée de 7 à 8 ans. Le père, Jacques, intéresse le héros par sa mine timide et bonhomme. Ils commencent à se serrer la main chaque soir. Pendant six mois, le héros ignore le métier de son voisin. Mais un jour, il le voit dans la rue habillé de noir, portant une bière : il est donc croque-mort. Le lendemain, le jeune homme essaie de lui montrer de la sympathie. Jacques lui avoue alors qu'il ne veut pas révéler son vrai métier à sa fille, et qu'il ôte son manteau noir dans l'escalier pour ne pas le lui montrer. Le jeune homme offre à Jacques la possibilité de déposer chez lui son habit de croque-mort et d'y faire sa toilette. Désormais, Jacques se rend chez le héros matin et soir pour se changer. Pendant ce temps, il lui raconte les histoires de son travail, de ses morts. Certains soirs, il rentre saoul et plus bavard que d'habitude, et jure de porter le héros en terre, lorsqu'il sera mort. C'est pourtant le croque-mort qui meurt le premier. Le conte se clôt sur une parole ironique d'un de ses collègues : « Le croquemort est croqué. »

On remarque d'emblée une analogie frappante entre le conte et L'Assommoir : un croque-mort s'offre pour porter en terre le protagoniste. Certaines différences sont cependant notables. Dans le conte, l'élément le plus significatif est l'ambivalence de ce personnage. À la différence de Bazouge, qui n'inspire que la peur à l'héroïne, Jacques suscite chez le héros à la fois amitié et effroi. Au début de l'histoire, il est présenté comme un bonhomme timide :

Cet homme, dans sa mine lugubre, gardait un bon sourire timide ; on eût dit un grand enfant de cinquante ans, se troublant, rougissant comme une fille. Il cherchait l'ombre, filait le long des murs avec l'humilité d'un forçat gracié23.

Cet homme qui cherche l'ombre et file le long des murs nous fait penser au père Bru, calme et modeste, qui suit Gervaise comme un chien docile. Cependant, son âge, 50 ans, le rapproche plutôt de Bazouge. Au surplus, lorsqu'il porte l'habit noir de croque-mort, sa figure devient tout d'un coup effrayante pour le héros, à l'instar de Bazouge. Le contraste entre les deux aspects du personnage était accentué dans la première version de 1865 :

Vous ne sauriez croire combien un bout d'étoffe change une figure. Lorsque Jacques entrait le matin chez moi, dans son honnête blouse blanche, avec sa face jaune et souriante, on sentait en lui un brave cœur, un ouvrier laborieux et franc. Lorsqu'il quittait le grenier, dans son manteau sombre, ce n'était plus le même homme. [...] L'honnête ouvrier, le père de famille devenait une créature funèbre, aux regards inquiets et cruels 24 .

Ainsi, deux figures contradictoires coexistent chez cet homme : celle d'un ouvrier honnête et celle d'un croque-mort funeste. Cette dualité ainsi mise en relief ne pourrait-elle pas correspondre à la division opérée entre Bazouge et le père Bru ? De même, des sentiments ambivalents envers Jacques surgissent chez le héros, qui éprouve tour à tour sympathie et effroi. Ne peut-on aussi penser que ces deux sentiments seront repris dans L'Assommoir pour le compte de Gervaise, mais en étant dirigés respectivement vers le père Bru et vers Bazouge? Rappelons-nous en effet l'amitié et la pitié que Gervaise gardait pour l'ancien ouvrier ${ }^{25}$. Ainsi, la figure ambiguë de Jacques est inscrite dans les premières versions de ce conte, comme s'il était le germe des deux personnages qui apparaîtront dans L'Assommoir dix ans après.

Ce n'est pas seulement la figure, mais aussi l'humeur de Jacques, qui est empreinte de duplicité. Voyons un passage de la première version, supprimé dans la version définitive :

Jacques, ces jours-là, m'effrayait davantage, et j'éprouvais une secrète terreur à le voir si gai et si sombre. Il venait, disait-il, de rencontrer des héritiers généreux qui l'avaient emmené pleurer en leur compagnie chez un marchand de vin :

23. Mon voisin Jacques, op. cit., p. 435.

24. Ibid., « Notes et variantes », p. 1402-1403.

25. «Elle [Gervaise] se prit surtout d'amitié pour un ancien ouvrier peintre, un vieillard de soixante-dix ans [...] » (L'Assommoir, op. cit., p. 552) ; « Mais la grande pitié de Gervaise était surtout le père Bru [...] » (ibid., p. 686). 


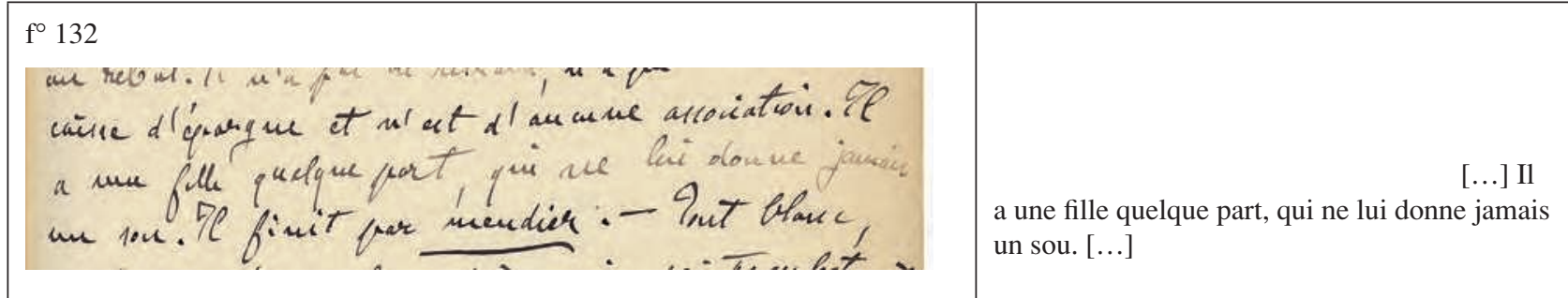

quelques litres et un morceau de brie sont des consolations suprêmes en pareil cas 26 .

Le mot «gai » est saisissant, puisque Jacques a été dessiné jusqu'ici en homme timide et modeste. D'ailleurs, les mots « gai » et «sombre » créent un effet paradoxal. C'est justement cette contradiction qui insinue dans le héros « une secrète terreur ». La phrase, tout en étant légèrement atténuée, maintient ce paradoxe dans les deuxième et troisième versions : «Jacques, ces soirs-là, m'effrayait presque : j'éprouvais une secrète épouvante à le voir si sombre et si gai27.»

Rappelons maintenant que Bazouge dans L'Assommoir est surnommé Bibi-la-Gaieté. Dès sa première entrée en scène, il apparaît saoul. D'ailleurs, dans les plans détaillés, Zola souligne toujours la gaieté de Bazouge. Dans le folio 38 que nous avons cité plus haut (le chapitre VIII du « Premier plan détaillé »), l'écrivain note : «Voir si Bazouge peut passer là comme un frisson. Le montrer très gai. Soûl toujours. » $\mathrm{Ou}$ encore, dans le folio 36 (le chapitre VII du « Deuxième plan détaillé »), Zola écrit : « Bazouge saoul » et note dans l'interligne au-dessus : «gai ». Derechef, dans le folio 77 (le chapitre XII du « Deuxième plan »), il note : « Lui toujours rigolo et galant. » L'humeur de Bazouge est donc constamment envisagée sur le registre de la gaieté enivrée. De là pouvons-nous imaginer que l'humeur complexe de Jacques soit décomposée de telle façon que la gaieté revienne à Bazouge et la morosité au père Bru.

\section{La présence de la fille}

L'analogie entre Jacques et Bazouge nous semble donc convaincante ; mais celle entre Jacques et le père
Bru ne paraît pas aussi évidente. Pour la discerner, il faut partir d'un indice dans le manuscrit consacré au père Bru. Reprenons, au folio 132 (ci-dessus), la fiche des personnages de L'Assommoir que nous avons examinée plus haut.

Cette indication montre que l'écrivain avait, au début de la conception du roman, l'intention de donner une fille au vieil ouvrier, alors que selon la version publiée celui-ci a trois fils qui sont morts en Crimée28. Si l'on se rappelle que Zola voulait aussi au départ donner à ce vieil ouvrier le métier de croque-mort, il est tentant de supposer quelque affinité entre la fille de ce folio, indifférente à son pauvre père, et l'enfant innocente du conte, à qui son père croque-mort voulait cacher son métier douteux. On pourrait même imaginer que le roman est une sorte d'extrapolation du conte : si Jacques n'était pas mort à la fin du conte, sa fille et lui auraient pu devenir au bout de vingt ans ce que le père Bru et sa fille ingrate sont l'un pour l'autre. Est-ce pousser trop loin l'imagination? Les deux points communs entre le père Bru et Jacques - la présence d'une fille et le métier de croque-mort - invitent en tout cas à associer ces deux personnages.

\section{Le sort de Jacques}

Ce que Mon voisin Jacques transmet de plus important à L'Assommoir touche pourtant au sort de Jacques. Certes, la conclusion ironique du conte est que tout le monde, y

26. Mon voisin Jacques, op. cit., p. 1404. L'épisode de quelques litres de vin et du fromage de brie offerts au croque-mort revient également dans L'Assommoir (p. 671).

27. Ibid.

28. « Il avait perdu ses trois fils en Crimée » (L'Assommoir, op. cit., p. 552). 
compris le croque-mort, témoin professionnel de la mort des autres, est soumis à la puissance du destin, nul ne pouvant échapper à la mort. Or Bazouge ne meurt pas dans le récit de L'Assommoir, il est porteur du Memento mori destiné à l'héroïne : il semble donc, à première vue, que la leçon du conte ne puisse s'appliquer à lui. Bazouge, au moins dans l'histoire, garde ainsi le rôle d'observateur de la vie humaine jusqu'à la fin. Mais c'est peut-être le père Bru qui partage le sort de Jacques, plutôt que Bazouge, en tant que mortel qui n'échappe pas à la roue du destin. La mort du père Bru devient plus signifiante si l'on prend en compte le fait qu'il est comme l'image en miroir de Gervaise. Car tous deux souffrent de la misère de l'existence ouvrière et meurent avachis l'un après l'autre. L'effet de miroir est mis en relief notamment dans la scène où, juste avant leur mort, ils se rencontrent par hasard dans la rue, l'un tombé dans la mendicité, l'autre dans la prostitution :

Tous deux se regardèrent. Ah ! mon Dieu ! Ils en étaient là, le père Bru mendiant, Mme Coupeau faisant le trottoir ! Ils demeuraient béants en face l'un de l'autre. [...] Avoir travaillé cinquante ans, et mendier! S'être vue une des plus fortes blanchisseuses de la rue de la Goutte-d'Or, et finir au bord du ruisseau ! Ils se regardaient toujours. Puis, sans rien se dire, ils s'en allèrent chacun de son côté, sous la neige qui les fouettait 29 .

Ils se regardent comme si chacun voyait sa propre image dans le miroir de l'autre. La juxtaposition des deux phrases et l'écho de leurs infinitifs initiaux «Avoir...» et «S'être... » accusent la symétrie de leur dégradation après toute une vie de travail.

Cette scène était déjà programmée dès le «Premier plan détaillé » des dossiers préparatoires, dans le chapitre XVIII ( $\left.f^{\circ} 78\right)$ : «Alors la scène sur les boulevards extérieur (sic). Personne ne veut d'elle. Elle rencontre le père Bru qui mendie. Le mendiant et la prostituée se regardant face à face. »

Par ailleurs, les scènes de la mort du père Bru et de Gervaise sont rapportées plus laconiquement que celles des autres personnages, comme si l'auteur voulait dire que la mort misérable est une chose banale, la conséquence ordinaire de la vie des ouvriers. Il note ainsi dans le chapitre XIII du « Deuxième plan détaillé » ( $\left.f^{\circ} 82\right)$ : « Le père Bru ayant été trouvé mort, on donne son chenil à Gervaise. Elle y meurt à son tour, sans drame, de misère et de lassitude, un avachissement final - Bazouge l'emporte, - et ce qu'il dit - ». Il n'y a pas de drame lorsqu'on meurt épuisé par la vie, puisque c'est la fatalité 30 . Si Bazouge reste à l'écart de cette fatalité, c'est le père Bru, reflet de Gervaise, qui hérite de celle subie par Jacques dans le conte et incarne la misère humaine.

On voit donc que l'ambiguïté propre au personnage de Jacques - la figure de la Mort et celle du mortel - se scinde nettement entre deux groupes de personnages dans L'Assommoir : le premier est représenté par Bazouge, qui se tient dans une perspective en surplomb sur la fatalité, et le second par le père Bru, Gervaise et d'autres, prisonniers du destin. Faire mourir le père Bru et laisser vivre Bazouge en tant qu'observateur : une telle dichotomie provient peut-être de la ramification du personnage d'origine, Jacques ${ }^{31}$.

\section{Les stratégies de composition des œuvres littéraires}

Mais pourquoi Zola a-t-il décomposé le caractère double de Jacques pour l'attribuer à deux personnages dans L'Assommoir ? Quelle est la nécessité de ce procédé de division ? Cette question fondamentale est étroitement liée à une autre, que nous soulevions à la fin de notre première partie, à propos de la distribution des entrées en scène des deux personnages.

29. Ibid., p. 773-774.

30. Au début de l'Ébauche, Zola assigne pour but à ce roman de décrire la vie des ouvriers : «Le roman doit être ceci : Montrer le milieu peuple, et expliquer par ce milieu milieu les mœurs peuple ; comme quoi, à Paris, la soûlerie, la débandade de la famille, l'ae les coups, l'acceptation de toutes les hontes et de toutes les misères vient des conditions mêmes de l'existence ouvrière, des travaux, durs, des promiscuités, des laisser-aller, etc. » ( $\left.\mathrm{f}^{\circ} 158\right)$. Par ailleurs, Zola s'est essayé à décrire les différents types de mort propres aux différentes classes sociales dans le recueil de contes Comment on meurt, initialement publié dans Le Messager de l'Europe en août 1876 sous le titre : Comment on meurt et comment on enterre en France.

31. À l'égard de la réutilisation d'un même type de personnage dans d'autres romans, il y a une autre anecdote : le père Bru, qui vient sans doute de Jacques, devient à son tour l'origine d'un autre personnage : Laveuve, un ouvrier de 70 ans, ancien peintre usé par le travail, que Zola reprendra au bout de vingt ans dans Paris (1898), le dernier volume du cycle des Trois Villes (voir Euvres complètes, t. VII, Paris, Cercle du Livre précieux, p. 1175). 


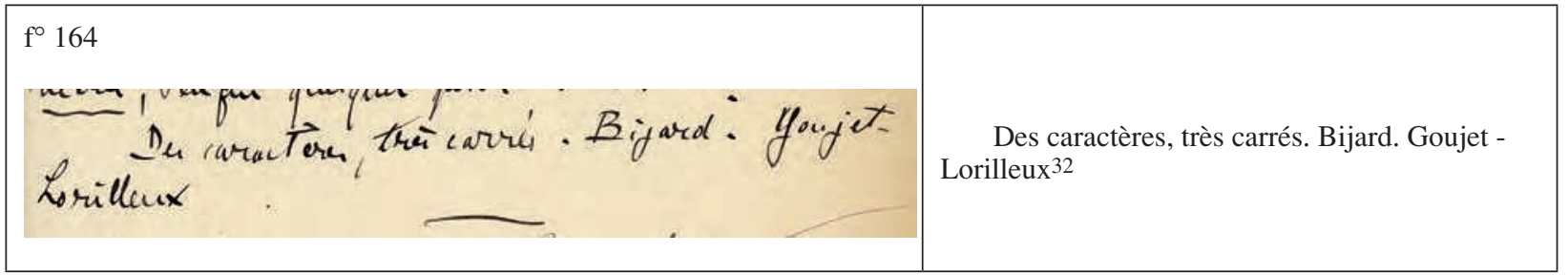

\section{Personnage principal et personnage secondaire}

Quand on compare les deux œuvres dont il est question ici, on discerne deux grandes différences. La première tient au genre littéraire : Mon voisin Jacques est un conte, tandis que L'Assommoir est un roman. La deuxième au statut du personnage sur le plan narratif : Jacques est le personnage principal, alors que Bazouge et le père Bru sont des personnages secondaires. Il est utile à ce propos de se référer au commentaire de l'auteur luimême. Dans l'Ébauche de L'Assommoir, au folio 163 cité plus haut, Zola écrit, avant d'énumérer les personnages secondaires masculins : "Les personnages secondaires doivent me servir à compliquer le récit. » Dans le folio suivant, il précise que ces personnages imaginés doivent avoir « des caractères carrés » (ci-dessus). Entendons par là qu'il s'agit pour l'écrivain de simplifier les caractères des personnages secondaires qu'il compte employer en attribuant à chacun d'eux une fonction propre, dans le but de tisser un récit plus complexe. Ces commentaires de l'auteur correspondent à la teneur de sa célèbre lettre sur Germinal, adressée à Henry Céard en 1885, où il admet qu'il caractérise les personnages secondaires d'un trait, tout en les opposant aux personnages principaux : «L'abstraction du personnage, chaque figure raidie, n'ayant plus qu'une attitude. [...] De là une simplification constante des personnages. Comme dans mes autres romans d'ailleurs, les personnages de second plan ont été indiqués d'un trait unique : c'est mon procédé habituel ${ }^{33}$.»

\section{Conte et roman}

Mais ce n'est pas tout : ce procédé consistant à créer des personnages au caractère simple est profondément lié à l'élaboration d'un récit romanesque au long cours. Zola entend donc se servir de plusieurs personnages secondaires qui, jouant leurs rôles univoques respectifs, enrichiront l'intrigue et multiplieront les épisodes constitutifs du roman. À l'inverse, un récit plus court - un conte - n'a pas besoin d'intrigue complexe, et peut donc se passer de cette assemblée nombreuse de personnages secondaires. Le récit court se concentre sur un petit nombre de personnages, devant ceux-ci peuvent cumuler des traits de caractère équivoques, ambivalents et indécis.

Or, Roger Ripoll a fait remarquer qu'à chaque réédition de Mon voisin Jacques, Zola a réduit graduellement la place consacrée au portrait de Jacques. Et ce critique de commenter : "Dans les versions de 1872 et 1874 notamment, Zola s'est appliqué à ôter au croque-mort le caractère inquiétant qu'il possédait en 1865 et, à un moindre degré, en 1866 et 186934 . » En effet, les descriptions de Jacques dans les premières versions avaient tendance à accentuer son caractère sinistre, par conséquent à souligner son ambivalence. Dans les dernières versions, en revanche, le contraste est devenu plus subtil, s'est adouci. Ainsi le protagoniste, loin de verser dans l'extravagance, se voit-il gratifié d'un portrait tout en nuances, homogène et vraisemblable.

32. Zola n'a pas encore, à ce stade, trouvé les noms de Bazouge ni du père Bru, mais c'est juste après cette note que le nom de Bazouge apparaît pour la première fois, plus bas dans ce même folio, comme on l'a vu dans la précédente section de cette étude.

33. « Lettre à Henry Céard, Paris 22 mars 1885 », dans Émile Zola, Correspondance 1884-1886, t. V, éd. B. H. Bakker, Montréal/Paris, Presse de l'université de Montréal/Éditions du CNRS, 1985, p. 249. Pour plus de détails sur le métalangage zolien dans les dossiers préparatoires qui sert à l'expression des hiérarchies entre les personnages, voir «Introduction » et le chapitre «Dispositio » dans Le Signe et la consigne. Essai sur la genèse de l' cuvre en régime naturaliste : Zola, dir. Philippe Hamon, Genève, Droz, 2009.

34. Mon voisin Jacques, op. cit., p. 1364. 
Cependant, lorsque l'auteur reprend ce portrait dans le processus d'une création romanesque, il en réinvestit les contradictions originelles pour camper deux personnages secondaires distincts. C'est ainsi que le contraste de la figure sinistre et de la gaieté effrayante chez Jacques, peu à peu effacé dans les dernières versions du conte, revit dans le portrait de Bazouge. Zola a ainsi adapté au genre romanesque la méthode de création des personnages qui consiste à extraire les éléments divers confondus dans la figure d'un protagoniste de récit court, et à les répartir entre des personnages secondaires qui peuvent, comme les pièces d'un jeu d'échecs, compliquer et enrichir un récit long. La répartition des entrées en scène des deux personnages a donc été probablement agencée dans le but de distinguer leurs fonctions respectives et d'en accroître l'efficacité stratégique 35 .

Dans son ouvrage Logiques du brouillon, Daniel Ferrer affirme : «l'œuvre est ce qui, parmi une multitude de possibles, est devenu nécessaire, tout en conservant la mémoire des possibilités évanouies ${ }^{36}$. » En effet, après l'élimination de tout ce qui était virtuellement possible, seul reste le nécessaire pour donner forme à l'œuvre. Cette démarche révèle ce qu'implique l'opération littéraire elle-même, le processus que l'œuvre exige de son créateur. Toutes nos explorations génétiques ont tendu à la mise au jour de ce « nécessaire » en fouillant « la mémoire des possibilités évanouies » et en la confrontant à l'œuvre réalisée.

Nous avons commencé par découvrir le dédoublement d'un personnage de «vieil ouvrier » dans les dossiers préparatoires de L'Assommoir, ce qui nous a amené à en chercher la source dans une des œuvres antérieures de Zola, le conte Mon voisin Jacques. À partir de la comparaison du conte et du roman, nous avons montré que la formation des personnages était en rapport étroit avec les procédés d'élaboration propres au genre romanesque. À observer la scission du portrait équivoque d'un protagoniste du conte en portraits univoques de personnages secondaires du roman, nous avons pu vérifier que l'auteur avait su tirer parti de ses meilleures intuitions créatives en les ajustant à chaque genre de récit.

35. Le procédé de dédoublement que nous avons analysé est symétrique de celui que Chantal Pierre-Gnassounou a établi, en montrant qu'il arrivait à Zola de renoncer à des personnages prévus dans les Ébauches, afin de préserver l'économie narrative et la logique de l'action. Voir Chantal Pierre-Gnassounou, « Dispersion et double emploi : les ratés de la structure dans les Ébauches des Rougon-Macquart », dans Zola, genèse de l'œuvre, Paris, CNRS Éditions, 2002, p. 89-102.

36. Daniel Ferrer, Logiques du brouillon. Modèles pour une critique génétique, Paris, Éditions du Seuil, coll. « Poétique », 2011, p. 171.

\footnotetext{
Midori NaKamura est née à Osaka (Japon) en 1978. Après avoir obtenu son Master en langue et littérature françaises à l'Université de Kyoto en 2005, elle a soutenu son mémoire de DEA à l'Université de Genève en 2006. En juin 2012, elle a soutenu sa thèse doctorale à l'Université Paris III sous la direction d'Alain Pagès. Elle y étudie la technique narrative de « l'annonce » dans les romans d'Émile Zola. Après avoir travaillé à l'Université Sophia (Tokyo) en tant que chercheuse postdoctorale, elle est professeur assistant à la Nagoya University of Commerce and Business.
} 


\section{Résumés \\ L'Assommoir et Mon voisin Jacques d'Émile Zola : étude comparée de la genèse des personnages secondaires}

Les personnages de second plan sont parfois eux aussi investis de fonctions spécifiques au récit. Une enquête sur la genèse des personnages de L'Assommoir (1877) d'Émile Zola nous permet de trouver les traces de la programmation. Dans l'Ébauche de ce roman, le croque-mort Bazouge, annonciateur de la mort de l'héroïne, est aussi un ouvrier incarnant la machine humaine usée par le travail et la misère. Mais la cohabitation des figures de croque-mort et d'ouvrier semble difficile, Zola crée donc deux personnages et renomme l'ouvrier «Bru » pour donner à Bazouge l'autre rôle. L'origine de ces deux personnages se trouve dans le conte Mon voisin Jacques, que Zola n'a cessé de récrire (1865-1874). Le caractère ambivalent du protagoniste de ce conte, le croque-mort Jacques, sera réparti sur deux personnages secondaires dans le roman postérieur : Bazouge héritera du côté sinistre pour incarner la Mort et Bru du côté bonhomme pour se charger de la figure du mortel. La multiplication des personnages et la simplification de leur caractère sont en rapport étroit avec les procédés d'élaboration propres au genre romanesque.

Secondary characters are sometimes in turn invested with functions specific to the story. An investigation of the genesis of the characters in Émile Zola's L'Assommoir (1877) allows us to detect the traces of the project. In the novel's draft, Bazouge the undertaker, a harbinger of the heroine's death, is also a worker embodying the human machine worn out by work and poverty. But this coexistence of the undertaker and the worker's figures was problematic, so Zola created two characters and renamed the worker "Bru" in order to give another role to Bazouge. The origin of the two characters can be found in the short story Mon voisin Jacques, which Zola constantly rewrote (18651874). The ambivalent personality of this story's main character, the undertaker Jacques, is divided between two secondary characters in the future novel: Bazouge will inherit the sinister side, so as to embody mortality, and Bru the ingenuous side, taking over the mortal's figure. The multiplication of characters and the simplification of their personality are closely linked to the elaboration processes specific to the genre of the novel.

Auch die Nebenfiguren sind manchmal mit für die Erzählung spezifischen Funktionen besetzt. Eine Untersuchung der Genese der Figuren von Émile Zolas L'Assommoir (1877) ermöglicht es uns, Spuren der Planung zu finden. Im Entwurf dieses Romans ist der Leichenbestatter Bazouge, der Verkünder des Todes der Heldin, auch ein Arbeiter, der die von Mühe und Misere verbrauchte menschliche Maschine verkörpert. Aber da es schwierig erscheint, die Figuren des Leichenbestatters und des Arbeiters zusammenzubringen, schafft Zola daraus zwei Personen und nennt den Arbeiter „Bru“, um Bazouge die andere Rolle zu geben. Der Ursprung dieser zwei Figuren findet sich in der Kurzgeschichte Mon voisin Jacques, die Zola mehrmals umgeschrieben hat (1865-1874). Der ambivalente Charakter des Protagonisten dieser Erzählung, des Leichenbestatters Jacques, wird im späteren Roman auf zwei sekundäre Figuren aufgeteilt: Bazouge erbt die unheimliche Seite, um den Tod zu verkörpern, und Bru die Seite des guten Mannes, um die Rolle des Sterblichen zu übernehmen. Die Vervielfachung der Figuren und die Vereinfachung ihres Charakters stehen in engem Zusammenhang mit den der Romangattung eigenen Erarbeitungsmethoden.
Los personajes de segundo plano tienen a veces también funciones específicas en el relato. Una investigación acerca de la génesis de los personajes de La taberna (1877) de Émile Zola nos ha permitido encontrar las huellas de la programación. En el esbozo de esta novela, el sepulturero Bazouge, anunciador de la muerte de la heroína, es también un obrero que encarna la máquina humana gastada por el trabajo y la miseria. Pero la cohabitación de las figuras del sepulturero y del obrero resulta difícil: Zola crea entonces dos personajes y bautiza al obrero "Bru", reservando el otro papel para Bazouge. El origen de estos dos personajes se encuentra en el cuento Mi vecino Jacques, que Zola ha reescrito incesantemente (1865-1874). El carácter ambivalente del protagonista de este cuento, el sepulturero Jacques, se repartirá entre dos personajes secundarios en la novela posterior: Bazouge heredará el lado siniestro para encarnar la Muerte y Bru el lado bonachón, tomando a su cargo la figura del mortal. La multiplicación de los personajes y la simplificación de sus caracteres están en estrecha relación con los procedimientos de elaboración propios del género novelesco.

As personagens de segundo plano têm às vezes também funções específicas na narrativa. $\mathrm{O}$ exame da génese das personagens de L'Assommoir (1877), de Émile Zola permite-nos encontrar vestígios de programação. No projecto deste romance, o coveiro Bazouge, anunciador da morte da heroína, era ainda um operário que encarnava a máquina humana desgastada por trabalho e miséria. Mas, como a coexistência das figuras de coveiro e operário parece difícil, Zola criou então duas personagens, chamou ao operário "Bru" e reservou a Bazouge o outro papel. A origem dessas duas personagens encontrase no conto Mon voisin Jacques, que Zola reescreveu incessantemente (1865-1874). O carácter ambivalente do protagonista desse conto, o coveiro Jacques, será repartido por duas personagens menores no romance posterior: Bazouge irá herdar a feição sinistra para encarnar a morte e a Bru caberá a feição mais simpática que carrega a figura mortal. A multiplicação de personagens e a simplificação do seu carácter são típicas dos processos de elaboração do género romanesco.

A volte, anche ai personaggi secondari vengono attribuite funzioni specifiche al racconto. Un'inchiesta sulla genesi dei personaggi de L'Assommoir (1877) di Émile Zola ci permette di ritrovare le tracce di tale programmazione Nell'abbozzo di questo romanzo, il becchino Bazouge, annunciatore della morte dell'eroina, è anche un operaio che incarna la macchina umana logorata dal lavoro e dalla miseria. Ma poiché la convivenza delle figure di becchino e operaio risulta difficile, Zola crea due personaggi: chiama l'operaio "Bru" e assegna a Bazouge l'altro ruolo. L'origine di questi due personaggi si trova nel racconto Mon voisin Jacques, che Zola ha riscritto incessantemente tra il 1865 e il 1874. Il carattere ambivalente del protagonista di questo racconto, il becchino Jacques, sarà ripartito fra i due personaggi secondari del romanzo successivo: Bazouge erediterà il lato sinistro, incarnando la Morte, e Bru il lato ingenuo, rivestendo la figura del mortale. La moltiplicazione dei personaggi e la semplificazione del loro carattere sono in stretto rapporto con i processi di elaborazione propri del genere romanzesco. 